\title{
Effect of red mud addition on tetracycline and copper resistance genes and microbial community during the full scale swine manure composting
}

\author{
Rui Wang ${ }^{\mathrm{a}, \mathrm{b}, 1}$, Junya Zhang ${ }^{\mathrm{a}, \mathrm{b}}$, Qianwen Sui ${ }^{\mathrm{a}, \mathrm{b}}$, Hefeng Wan ${ }^{\mathrm{c}}$, Juan Tong ${ }^{\mathrm{a}, \mathrm{b}}$, Meixue Chen ${ }^{\mathrm{a}, \mathrm{b}, 1}$, \\ Yuansong Wei ${ }^{\mathrm{a}, \mathrm{b}, \mathrm{d}, *}$, Dongbin Wei ${ }^{\mathrm{a}}$ \\ ${ }^{a}$ State Key Joint Laboratory of Environmental Simulation and Pollution Control, Research Center for Eco-Environmental Sciences, Chinese Academy of Sciences, Beijing 100085, \\ PR China \\ ${ }^{\mathrm{b}}$ Department of Water Pollution Control Technology, Research Center for Eco-Environmental Sciences, Chinese Academy of Sciences, Beijing 100085, PR China \\ ${ }^{\mathrm{c}}$ Nanchang University, Nanchang 100123, PR China \\ d University of Chinese Academy of Sciences, Beijing 100049, PR China
}

\section{H I G H L I G H T S}

- ARGs could be effectively removed through the thermophilic composting process.

- The main contributor of reducing ARGs abundance was pile temperature.

- Bacterial community was the main driver to reduction of ARGs abundance.

- Addition of red mud indeed hindered removal of ARGs during composting.

\section{A R T I C L E I N F O}

\section{Article history:}

Received 17 March 2016

Received in revised form 28 May 2016

Accepted 2 June 2016

Available online 4 June 2016

\section{Keywords:}

ARGs

Copper resistance genes

Swine manure

Red mud

Composting

\begin{abstract}
A B S T R A C T
Swine manure has been considered as the reservoir of antibiotic resistance genes (ARGs). Composting is one of the most suitable technologies for treating livestock manures, and red mud was proved to have a positive effect on nitrogen conservation during composting. This study investigated the abundance of eight tetracycline and three copper resistance genes, the bacterial community during the full scale swine manure composting with or without addition of red mud. The results showed that ARGs in swine manure could be effectively removed through composting (reduced by $2.4 \log$ copies/g TS), especially during the thermophilic phase (reduced by $1.5 \log$ copies/g TS), which the main contributor might be temperature. Additionally, evolution of bacterial community could also have a great influence on ARGs. Although addition of red mud could enhance nitrogen conservation, it obviously hindered removal of ARGs (reduced by 1.7 log copies/g TS) and affected shaping of bacterial community during composting.
\end{abstract}

(C) 2016 Elsevier Ltd. All rights reserved.

\section{Introduction}

In concentrated animal feeding operations (CAFOs), antibiotics are routinely used to control and prevent diseases at therapeutic doses, and to promote growth at subtherapeutic doses (Koike et al., 2007). In 2000, more than 227,000 tons of antibiotics were produced in the United States and almost half of them were used as feed additives (Sarmah et al., 2006). In China, 210,000 tons of

\footnotetext{
* Corresponding authors at: State Key Joint Laboratory of Environmental Simulation and Pollution Control, Research Center for Eco-Environmental Sciences, Chinese Academy of Sciences, Beijing 100085, PR China.

E-mail address: yswei@rcees.ac.cn (Y. Wei).

1 These authors contributed equally to this work.
}

antibiotics are produced every year, and $48 \%$ of them were applied in the agriculture and livestock industry (Luo et al., 2010). However, these antibiotics are poorly absorbed in animal digestive system, and $50-80 \%$ is excreted through feces and urine as maternal or metabolic products (Sarmah et al., 2006). Antibiotic resistant bacteria (ARB) and antibiotic resistance genes (ARGs) can be induced under the selective pressure of antibiotics in animal guts, particularly when antibiotics are used at subtherapeutic levels, resulting in animal manure being a potential reservoir for dissemination of ARB and ARGs into the environment (Mackie et al., 2006; Heuer et al., 2011).

Tetracyclines (TCs) are broad-spectrum antibiotics that are used extensively in the livestock industry and tetracycline resistance genes have been detected and reported widely in the environments 
surrounding a pig farm (Wu et al., 2010). Currently, more than 40 classes of tetracycline resistance genes (tet) have been described and studied in various environments, including three resistance mechanisms (efflux pump proteins, ribosomal protection proteins (RPPs), and inactivating enzymes) (Roberts, 2005). Tetracycline resistance has already emerged in many commensal and pathogenic bacteria because of tet genes acquisition (Chopra and Roberts, 2001).

Copper, in the forms of copper sulfate and copper chloride, are frequently overused as feed additives to promote growth and control disease in intensive livestock production (Nicholson et al., 1999). However, there is growing concern that heavy metal, such as copper, functions as a selective agent in the proliferation of antibiotic resistance through co-selection (Baker-Austin et al., 2006). In microorganisms, copper resistance is mainly mediated by three different systems: the efflux ATP-ase pump CopA, which is able to extrude copper ions; the chemo-osmotic copper extrusion cus system, responsible for heavy metal export; and the periplasmic pco system, which encodes a multi-copper oxidase protein PcoA that is responsible for oxidation of $\mathrm{Cu}(\mathrm{I})$ in the periplasmic space (Besaury et al., 2013). The pco system is only found on plasmid pRJ1004, which was isolated from Escherichia coli in the gut flora of pigs fed a diet supplemented with copper sulfate. The copper resistance specified by this plasmid is encoded by the pco gene cluster, which contains seven genes, pcoABCDRSE (Lee et al., 2002).

Composting is one of the most suitable technologies for treatment and disposal of livestock manures, along with mass reduction, sanitation and resource regeneration (Jiang et al., 2011). During the aerobic thermophilic composting process, complex and unstable organic matter is converted into relatively stable humus-like material, which can be handled, stored, and used as a soil conditioner and fertilizer (Li et al., 2013). However, nitrogen loss in the form of ammonia is a significant problem. Its loss reduces compost product quality and results in malodorous environments (Chan et al., 2016). Mineral substances such as zeolite and red mud, which contain a large amounts of $\mathrm{Mg}$, have been showed to have a positive effect on the conservation of nitrogen in composts, because $\mathrm{N}$ and $\mathrm{P}$ in compost materials can form a stable compound like struvite $\left(\mathrm{NH}_{4} \mathrm{Mg}\left(\mathrm{H}_{2} \mathrm{O}\right)_{6}\left[\mathrm{PO}_{4}\right]\right)$ with $\mathrm{Mg}$ provided (Chan et al., 2016; Zhao et al, EEMJ accepted).

To the best of knowledge, no study has yet investigated the impact of adding red mud on the abundance and variation of copper and tetracycline resistance genes during the full scale swine manure composting. High throughput sequencing, a new method to study bacterial community structure, has increased capacity for discovery of unknown microorganisms and provided a more comprehensive view of microbial biodiversity (Petrosino et al., 2009). Therefore, the purpose of this study was to investigate the impact of added red mud on the distribution and fate of tetracycline (tetA, tet $\mathrm{B}$, tet $\mathrm{C}$, tet $\mathrm{L}$, tet $\mathrm{M}$, tet $\mathrm{O}$, tet $\mathrm{W}$, tet $\mathrm{X}$ ) and copper ( $p c o \mathrm{~A}, p \operatorname{coC}, p \operatorname{co\mathrm {D}})$ resistance genes during the full scale swine manure composting. In addition, the bacterial community structure was also analyzed using a high throughput sequencing method to discover drivers of evolution of these genes during swine manure composting.

\section{Materials and methods}

\subsection{The full scale swine manure composting}

Swine manure composting was carried out in two windrow tests, including an experimental test with adding red mud (RM) and a control test (CK) without red mud from July 21 to September 11,2012 , in a windrow composting plant located in a suburb of Beijing (N 3942', E $116^{\circ} 38^{\prime}$ ). Raw materials for composting were swine manure collected from swine farms nearby and mushroom residues used as an amendment to adjust the $\mathrm{C} / \mathrm{N}$ ratio to $1: 4(\mathrm{v} /$ v). The $\mathrm{pH}$ value of red mud (Shangdong Aluminum Company of China) was adjusted from 12.21 to 7.10 with sulfuric acid at $1.8 \mathrm{~mol} / \mathrm{L}$. The major ion contents of red mud (shown in Table 1) were measured by a full spectrum of direct reading plasma atomic emission spectroscopy (Prodigy, Leemans, America, USA) in order to calculate the amount of red mud to add. The amount of modified red mud $(87.95 \mathrm{~kg})$, determined by swine manure total nitrogen (TN) according to Eqs. (1) and (2) (Support Information) was added and mixed evenly with swine manure and mushroom before composting. The TN content in the red mud added test was $1.8 \mathrm{~g} \mathrm{~kg}^{-1}$ higher than that in the control test at the end of the full scale swine manure, which showed the addition of red mud did have somewhat effect on nitrogen conservation (Zhao et al, EEMJ accepted).

Parameters of all composting materials, including $\mathrm{pH}$, moisture content, organic matter, TOC and TN were determined according to the methods (Bao, 2000) and the results are showed in the Table 1. The size of the windrow pile was about $27 \mathrm{~m}^{3}$, at the length of $30 \mathrm{~m}$, the height of $0.9 \mathrm{~m}$ and the width of $2 \mathrm{~m}$ at the bottom of the pile. The full scale windrow composting was operated in the open air and turned by a turner (BACKHUS 15.30, Germany) on days 3, 9, 17, and 25 during the thermophilic stage, respectively. During the composting process, water was added irregularly to maintain stable moisture content of the composting materials at about $50 \%$. The pile temperature, in the upper, central and lower part of pile, was recorded every day. The composting material was sampled by mixing the upper, central and lower sites of the pile on days $1,3,7,14,21,28,35,42$ and 53 . All of the samples collected were kept at $4{ }^{\circ} \mathrm{C}$ to transport to laboratory for further analysis.

\subsection{Genomic DNA extraction}

Composting materials (approximately $20 \mathrm{~g}$ ) were collected in triplicate from each site of the composting pile and mixed evenly. Mixed samples $(0.2 \mathrm{~g}$ ) were collected in $2 \mathrm{~mL}$ sterilized tubes for total DNA extraction with QIAamp DNA Stool Mini Kit (QIAGEN; Solon, $\mathrm{OH}$ ) according to the manufacturer's instructions. The concentration and quality of the extracted DNA was determined by a NanoDrop 1000 spectrophotometer analysis (NanoDrop, USA) and $1.5 \%(\mathrm{w} / \mathrm{v})$ agarose gel eletrophoresis. DNA extracts were stored at $-20^{\circ} \mathrm{C}$ until needed.

\subsection{Quantitative real time PCR}

DNA extractions on days 1, 3, 7, 14, 21, 28, 35, 42 and 53 were used for quantitative real time PCR (qPCR) to quantify the eight tetracycline resistance genes (efflux pump: tet $\mathrm{A}$, tet $\mathrm{B}$, tetC, tet $\mathrm{L}$;

Table 1

Characteristics of raw materials in the full scale swine manure composting.

\begin{tabular}{|c|c|c|c|c|}
\hline \multirow[t]{2}{*}{ Characteristics } & \multicolumn{4}{|c|}{ Materials } \\
\hline & $\begin{array}{l}\text { Swine } \\
\text { manure }\end{array}$ & $\begin{array}{l}\text { Mushroom } \\
\text { residues }\end{array}$ & Mixture & $\begin{array}{l}\text { Red } \\
\text { mud }\end{array}$ \\
\hline $\mathrm{pH}$ & 7.10 & 6.21 & 7.27 & 12.21 \\
\hline Moisture (\%) & 70.95 & 57.48 & 52.1 & $17.60 \%$ \\
\hline Organic matter (\%) & 77.86 & 91.56 & 78.13 & 1 \\
\hline $\mathrm{TOC}^{\mathrm{a}}\left(\mathrm{g} \mathrm{kg}^{-1}\right)$ & 451.6 & 531.1 & 453.2 & i \\
\hline $\mathrm{TN}^{\mathrm{b}}\left(\mathrm{g} \mathrm{kg}^{-1}\right)$ & 36.85 & 22.88 & 24.85 & i \\
\hline$C: N$ & 9.15 & 18.26 & 12.64 & i \\
\hline $\mathrm{Ca}\left(\mathrm{mg} \mathrm{g}^{-1}\right)$ & 1 & 1 & 1 & 113.05 \\
\hline $\mathrm{Mg}\left(\mathrm{mg} \mathrm{g}^{-1}\right)$ & 1 & 1 & 1 & 5.92 \\
\hline $\mathrm{Al}\left(\mathrm{mg} \mathrm{g}^{-1}\right)$ & 1 & 1 & 1 & 80.97 \\
\hline $\mathrm{Fe}\left(\mathrm{mg} \mathrm{g}^{-1}\right)$ & 1 & I & i & 125.43 \\
\hline
\end{tabular}

a Total organic carbon.

b Total nitrogen. 
ribosomal protection protein: tetO, tetM, tetW; enzymatic modification: tetX), three copper resistance genes (pcoA, pcoC and pcoD), and the 16S rRNA gene. Primers are described in the Supporting Information (Table S1).

The qPCR analysis was conducted using an ABI7300 apparatus (Applied Biosystems, USA). Each qPCR run consisted of 2 min initial denaturation at $95^{\circ} \mathrm{C}$, followed by 40 cycles of denaturation at $95{ }^{\circ} \mathrm{C}$ for $10 \mathrm{~s}$, and annealing and extension at $60{ }^{\circ} \mathrm{C}$ for $40 \mathrm{~s}$. A $25 \mu \mathrm{L}$ reaction mixture contained $12.5 \mu \mathrm{L}$ of $2 \times$ Power SYBRGreen qPCR Master Mix (Applied Biosystems, USA), $0.5 \mu \mathrm{L}$ each of forward and reverse primers $(10 \mu \mathrm{M}), 2 \mu \mathrm{L}$ of template DNA and $9.5 \mu \mathrm{L}$ of $\mathrm{dd}_{2} \mathrm{O}$. Samples were analyzed in triplicate independent qPCR runs, with a standard curve and negative control included in each run. The quantity of target DNA in unknown samples was calculated based on a standard curve generated using known quantities of template DNA. Standards for qPCR were prepared by PCR amplification of genes from positive controls, followed by ligation into the pMD-18T cloning vector according to the manufacturer's instructions (Takara), followed by transformation into JM109 Escherichia coli (Takara). Plasmids were purified using SK1191 UNIQ-10 kit (Sangon Biotech, Shanghai, Co., Ltd. CN). 10-Fold serial dilutions of plasmid DNA were prepared and run on a thermal cycler to generate standard curves $\left(\mathrm{R}^{2}>0.99\right)$. Following $\mathrm{qPCR}$, melting curves were generated automatically and analyzed to verify that nonspecific amplification did not occur.

In this study, gene quantities were calculated per total solid (TS) compost content, because the total quantity of genes was of greatest importance. An alternative approach was also used, normalizing gene quantities by the number of $16 \mathrm{~S}$ rRNA gene copies, which is a measure of total bacterial biomass. Both sets of data revealed similar patterns, and the gene quantity data normalized to $16 \mathrm{~S}$ rRNA genes is in the Supporting Information.

\subsection{Bacterial community analysis}

\subsubsection{DNA extraction, PCR amplification and sequencing}

The triplicate DNA extractions on days 1, 7, 21, 35, and 53 were merged for the following PCR amplification. PCR primers $515 \mathrm{~F}$ (GTGCCAGCMGCCGCGGTAA) and 806R (GGACTACHVGGGTWTCTAAT) targeting the bacteria and archaeal V4 region were selected for microbial community structure analysis according to the protocol described in Caporaso et al. (2010). These primers have been used in other microbial diversity studies such as the Earth Microbiome Project (http://www.earthmicrobiome.org/). The reverse primer contained a 6-bp error-correcting barcode unique to each sample, which permuted to allow the identification of individual samples in a mixture of a single Illumina Miseq sequencing run. DNA was amplified in triplicate for each sample, following the previously described protocol (Caporaso et al., 2010). The size of PCR amplicons was determined by agarose gel electrophoresis. PCR amplicons were purified with a DNA purification kit (Bioflux, Japan), and the concentrations were determined by NanoDrop1000 spectrometry (Thermo Scientific, Wilmington, DE, USA). Amplicons from different samples were mixed to achieve equal mass concentrations in the final mixture, which was sent to Novogene Co., Ltd., Beijing, for small-fragment library construction and paired-end sequencing using an Illumina MiSeq $\times 250$ sequencing system (Illumina, USA).

\subsubsection{Post run analysis}

Sequencing reads were assigned to each sample according to the unique 6-bp barcode, and then barcodes and primers were removed. Pairs of reads from the original DNA fragments were merged using FLASH, a fast and accurate software tool designed to merge pairs of reads when the original DNA fragments are shorter than twice the length of the reads. The overlapped reads, called "raw reads", were filtered by QIIME quality filters (Caporaso et al., 2010). Default settings for Illumina processing in QIIME were used $(\mathrm{r}=3, \mathrm{p}=0.75, \mathrm{q}=3, \mathrm{n}=0)$ : ( $\mathrm{r}$ ) max_bad_run_length: maximum number of consecutive low-quality base calls allowed before truncating a read; (p) min_per_read_length: minimum number of consecutive high-quality base calls to retain a read (as a percentage of total read length); (q) phred_quality_score: last quality score considered low quality; (n) sequence_ max_n: maximum number of ambiguous $(\mathrm{N})$ characters allowed in a sequence. PCR chimeras were filtered out using UCHIME (Edgar et al., 2011). Finally, after applying these filters, the reads were considered "clean reads". The average length of clean reads was $253 \mathrm{bp}$. All clean reads were uploaded to MG-RAST (http://metagenomics.anl.gov, project No. $=16381$ ).

Taxonomic classification of the sequences from each sample was carried out individually using the RDP Classifier. A bootstrap cutoff of 50\% suggested by the RDP was used to assign the sequences to different taxonomy levels. Rarefaction curves, $\mathrm{H}^{\prime}, \mathrm{E}$, varH, and Chao1 richness indices were calculated using the relevant RDP modules, including Rarefaction and Chao1 Estimator, as described previously (Zhang et al., 2016).

\subsection{Data analysis}

Statistical calculations and data analysis were performed using the SPSS 16.0 statistical software package (IBM, USA) and Origin 9.0 (Origin Lab, USA). A heat map of the top 41 families in each sample was built using HemI (http://hemi.biocuckoo.org/). According to the relative content of each family based on the classification, a principal component analysis (PCA) was performed using Canoco 5.0 (Microcomputer Power, USA).

\section{Results and discussion}

\subsection{Changes of pile temperature}

The trend of pile temperatures in both the control and the red mud added tests was similar which both experienced the thermophilic and mature stage (Fig. 1). The pile temperatures of the red mud added were a little higher than that of the control. The experiment was carried out in July in Beijing, when the ambient temperatures fluctuated around $30^{\circ} \mathrm{C}$; the pile temperatures were generally above $55^{\circ} \mathrm{C}$ during the composting process (from approximately days 5 to 45 ). Therefore, the thermophilic stage (lasting around 40 days) observed in this study seemed much

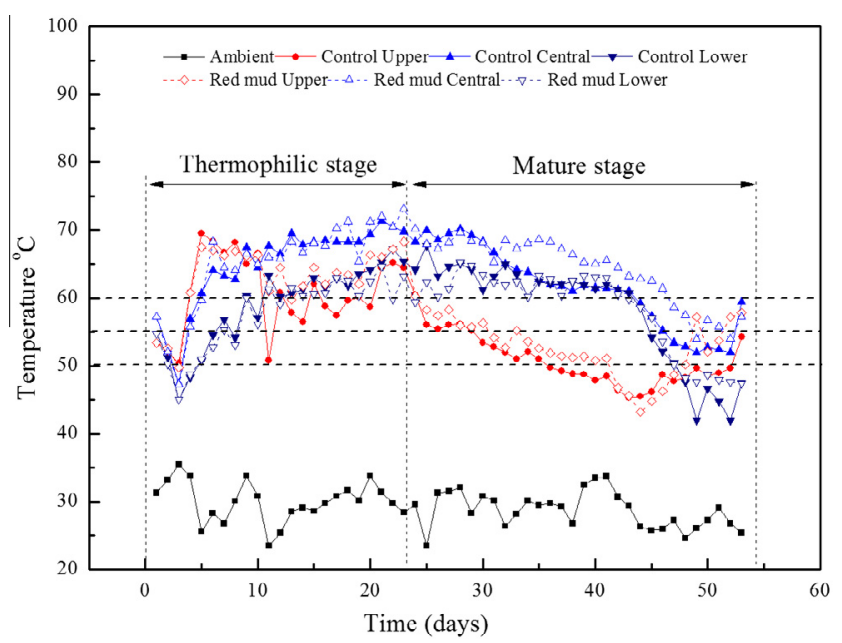

Fig. 1. Changes of pile temperatures during the full scale swine manure windrow composting. 
longer than theoretically predicted (around 23 days), and it was assumed to be one of the main contributors to bacterial community evolution during composting. Both pile temperatures reached $55^{\circ} \mathrm{C}$ rapidly in the first week, meeting the sanitary standard requirement for non-hazardous treatment of night soil in China (GB-7959-87). There were two obvious temperature fluctuations (on days 3 and 11) during the thermophilic stage because of heavy rains. Additionally, the pile temperatures of the central layer were much higher than that of either the bottom or the top. The maximum pile temperatures observed were above to $70^{\circ} \mathrm{C}$ during the composting. After the thermophilic stage, the pile temperatures decreased during a relatively short mature stage.

The temperature in a compost pile determines the evolution of microbial communities, and it is concerned with the hygienization of harmful microbes (Rainisalo et al., 2011). In general, high temperatures are a result of biological activity and are considered a necessary condition for successful composting (de Bertoldi et al., 1983). Mesophilic microorganisms are initially present in a compost pile, and their activity raises the pile temperature (Poincelot, 1975). As the pile temperature keeps climbing, thermophilic microorganisms gradually become predominant during the thermophilic stage, and parts of organic matter are decomposed at the same time, generating a substantial amount of heat. During the mature stage, the pile temperature decreases. Mesophilic microorganisms continue to decompose complex organic matter, and the compost is in anaerobic condition, because it is no turned (Miyatake and Iwabuchi, 2006).
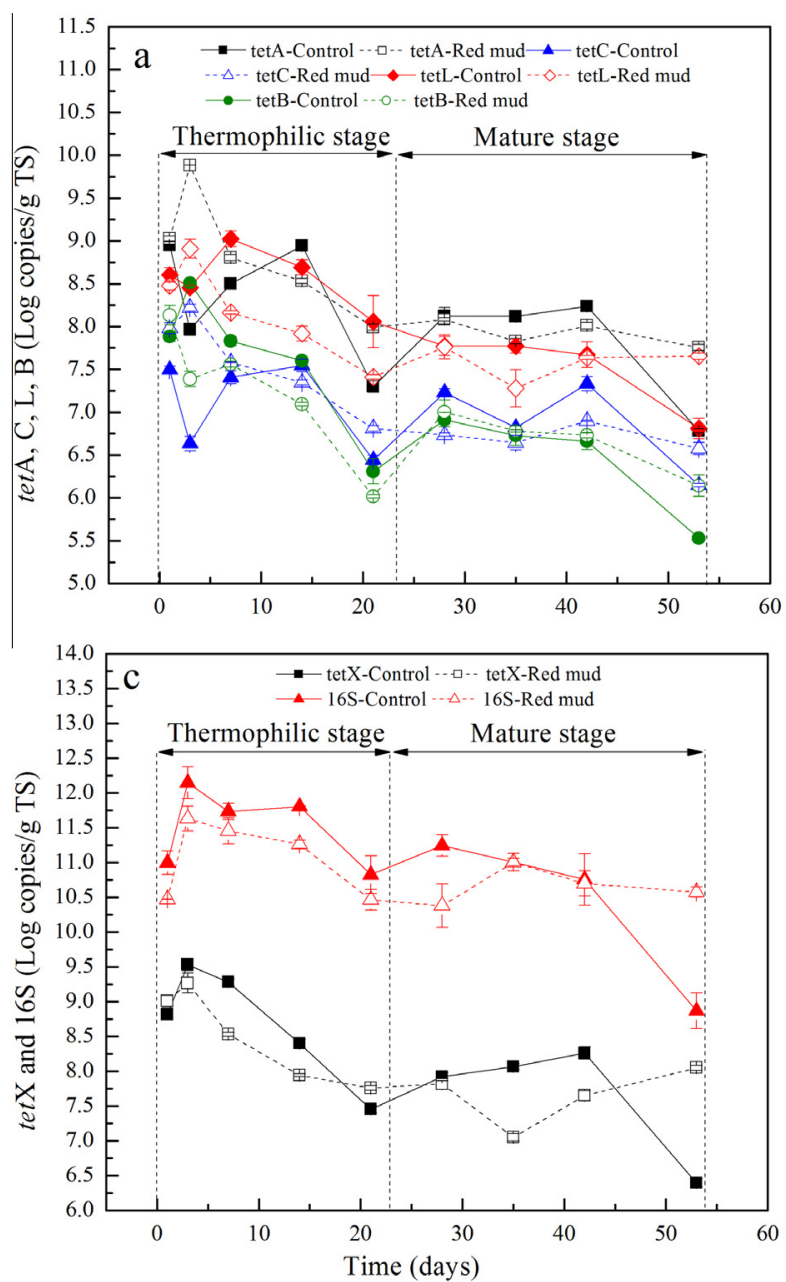

Other parameters of composting such as organic matter, moisture content, $\mathrm{pH}$ and Electrical Conductivity (EC) are described and discussed in the Support Information (Fig. S1).

\subsection{Reduction of resistance genes}

Quantities of the eight tet genes, the three pco genes, and the 16S rRNA gene in the composting materials ranged from 5.28 to $9.88,4.33$ to 8.91 , and 8.86 to $12.14 \log$ copies/g TS, respectively (Fig. 2). Quantities of each of these genes decreased over the composting period. According to the result of the $T$-test comparing all of these resistance genes, there was no significant difference $(p<0.05)$ in tet and pco variations between the control test and the red mud added test. However, the absolute reduction quantities (log copies/g TS) of almost every resistant gene in the control test were significantly higher than that that in the red mud added test (Table 2). This might imply that the addition of red mud somehow affected the reduction of ARGs during composting. Major reductions in ARGs occurred in the thermophilic phase (before day 21) (Table 2), with an average removal value of around $1.5 \log$ copies/g TS in both CK (1.51) and RM (1.47) tests. The average removal values of the mature were 0.8 and $0.2 \log$ copies/g TS in the CK and RM tests, respectively. These results indicated that the pile temperature might be one of main correlates of ARGs reduction. Additionally, differences between the removal rates of CK and RM occurred mainly in the mature stage. A possible reason might be that the addition of red mud significantly affected the
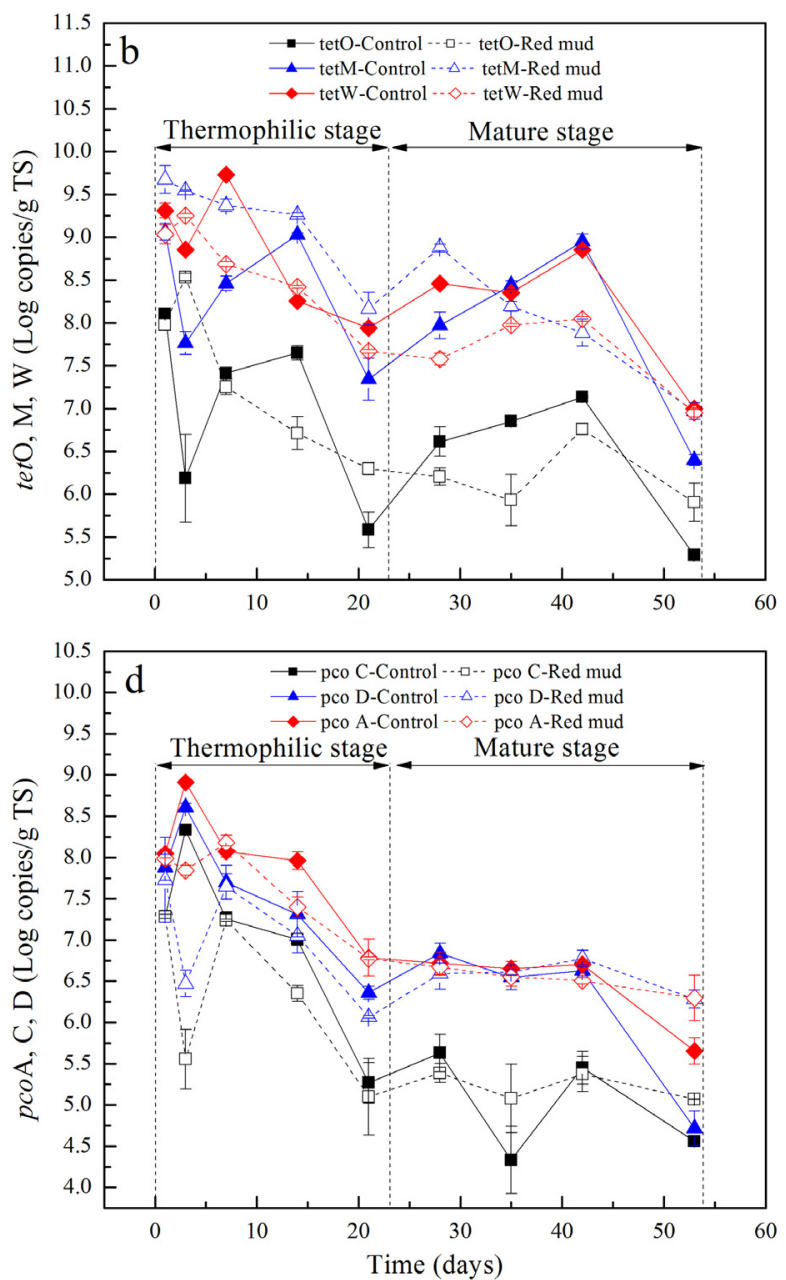

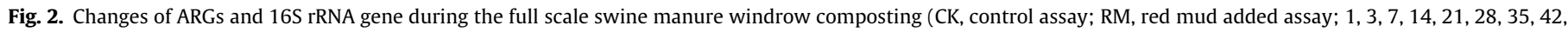
and 53 represent the days of samples collection). 
Table 2

ARGs reductions in the thermophilic and mature phase of swine manure composting.

Genes removal values (log copies/g TS) in Genes removal values (log copies/g TS) in

\begin{tabular}{|c|c|c|c|c|c|c|}
\hline & \multicolumn{3}{|c|}{ CK } & \multicolumn{3}{|c|}{$\mathrm{RM}$} \\
\hline & whole & thermophilic & mature & whole & thermophilic & mature \\
\hline & process & stage & stage & process & stage & stage \\
\hline $\operatorname{tet} \mathrm{A}$ & 2.1697 & 1.6520 & 0.5177 & 1.2720 & 1.0341 & 0.2379 \\
\hline tet $\mathrm{C}$ & 1.3497 & 1.0549 & 0.2948 & 1.4031 & 1.1690 & 0.2341 \\
\hline$t e t \mathrm{~L}$ & 1.7901 & 0.5452 & 1.2449 & 0.8222 & 1.0661 & -0.2439 \\
\hline tet $\mathrm{B}$ & 2.3555 & 1.5753 & 0.7803 & 1.9897 & 2.1173 & -0.1276 \\
\hline tet $\mathrm{O}$ & 2.8136 & 2.5187 & 0.2948 & 2.0739 & 1.6826 & 0.3913 \\
\hline tet $\mathrm{M}$ & 2.6646 & 1.7202 & 0.9444 & 2.7023 & 1.5068 & 1.1954 \\
\hline $\operatorname{tet} \mathrm{W}$ & 2.3115 & 1.3681 & 0.9434 & 2.0818 & 1.3657 & 0.7160 \\
\hline tet $\mathrm{X}$ & 2.4254 & 1.3655 & 1.0599 & 0.9588 & 1.2465 & -0.2877 \\
\hline$p c o \mathrm{C}$ & 2.7244 & 2.0157 & 0.7087 & 2.2133 & 2.1817 & 0.0315 \\
\hline$p c o \mathrm{D}$ & 3.1662 & 1.5209 & 1.6453 & 1.4461 & 1.6638 & -0.2177 \\
\hline pcoA & 2.3939 & 1.2612 & 1.1328 & 1.6931 & 1.2157 & 0.4774 \\
\hline
\end{tabular}

This table is red-yellow-green color gradation table, red color means higher value and green color means lower value.

variation of microbial community which was considered to be another main factor affecting ARGs variation (discussed in next section).

Other studies have also indicated that one of the dominant factors affecting the removal of AGRs was temperature (Diehl and Lapara, 2010; Su et al., 2015), e.g. the removal rates and removal efficiencies of tet genes increased along with an increase of temperature $\left(37^{\circ} \mathrm{C}, 46{ }^{\circ} \mathrm{C}\right.$ and $\left.55^{\circ} \mathrm{C}\right)$ during anaerobic digestion. Selvam et al. (2012) demonstrated that the thermophilic temperature seemed to play an important role in mitigating the abundance of ARGs in swine manure composting. In this study, there were obvious reductions in tet and pco genes between day 14 and 21 (Fig. 2, Fig. S2). The temperature during this period increased rapidly and exceeded $70^{\circ} \mathrm{C}$, which could destroy strict mesophilic and anaerobic bacteria (Su et al., 2015). The other significant reductions in tet and pco occurred between days 42 and 53. At this time, the composting pile had already been the mature stage, and there was no pile turning during this period. The temperature decreased dramatically in the last several days of the composting process. It seems that the significant reductions in tet and pco might be attributed to the obvious variation in temperature at the end of composting.

The quantities of all tet and pco genes showed a strong positive correlation (Table S2) in the present study. This might be attributable to co-resistance between antibiotics and heavy metals, which would mean that different resistance determinants were present on the same genetic element (Baker-Austin et al., 2006).
Gene quantities were also normalized to $16 \mathrm{~S}$ rRNA genes to indicate the proportion of bacteria carrying resistance genes (Fig. S3). Both tetracycline and copper resistance genes showed greater removal efficiency at the end of the thermophilic stage; nevertheless, they increased gradually at the end of the mature stage. The percentages of the tet genes were much higher than that of the pco genes. Among the tet genes, tet $\mathrm{W}$ and tet $\mathrm{M}$ were the predominant genes throughout the composting process.

\subsection{Evolution of bacterial communities}

The composition of the bacterial communities displayed temporal variations during the composting process by comparing the composition and structure of bacterial 16S rRNA genes obtained by high throughput sequencing. As shown in Fig. 3, Bacteroidetes, Firmicutes and Proteobacteria were the main phyla in all samples; however, the proportions of these bacteria were significantly different. In fresh swine manure, Bacteroidetes (40\%) were the most abundant bacteria, followed by Firmicutes (29\%) and Proteobacteria (22\%) (Fig. S4). However, as composting progressed, these populations changed in distinct ways. At the beginning, Bacteroidetes decreased dramatically to $10 \%$ and $8 \%$ in the control and red mud added tests, respectively, and then fluctuated around this level throughout the rest of the composting process. The large differences in these bacterial population changes (approximately 30\%) between fresh manure and compost materials might reflect the change in habitat from animal guts to open air compost (Fig. S4). 


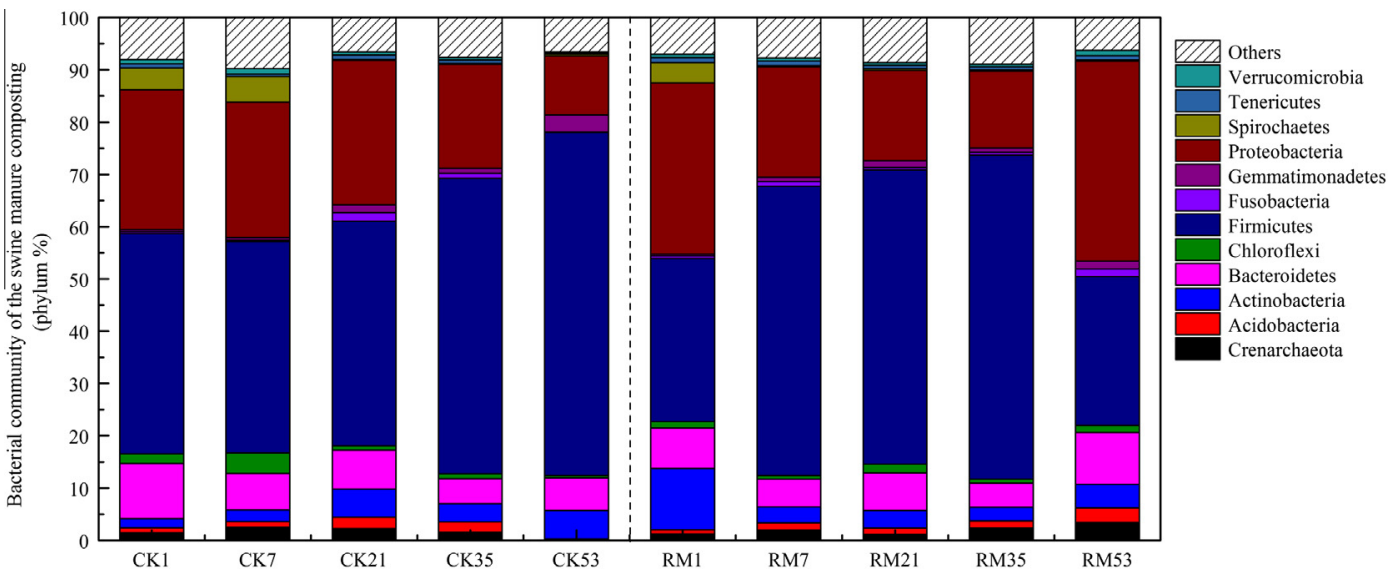

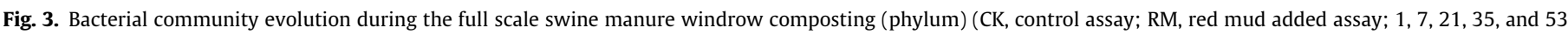
represent the days of samples collection).

For a detailed analysis of the bacterial community structures, 41 abundant families (abundance $>1 \%$ in any sample) were selected, and their abundances were compared (Fig. 4). The family level was selected to avoid biasing the interpretation, as suggested in a previous study (Shen et al., 2013). In fresh swine manure, the majority of microbes belonged to the family Prevotellaceae (phylum Bacteroidetes) at an abundance of $20.32 \%$. However, these bacteria decreased dramatically to $0.16 \%$ and $0.09 \%$ on day 1 in the control and red mud added tests, respectively, and then remained relatively stable at this level throughout the rest of the composting process. Prevotellaceae are strict anaerobic intestinal microflora that can degrade carbohydrates into acetic acid, succinic acid, lactic acid and other products (Alauzet et al., 2010). Because their environments changed from animal guts to compost materials, their abundance decreased quickly at the beginning of this experiment. However, as none of the resistance genes quantified in this study showed a positive correlation with the bacterial abundances
(Table S4), reductions in these bacteria did not contribute to the reduction in ARGs.

Firmicutes were the most abundance bacteria throughout the composting process (Fig. 3). These bacteria exhibited an increasing trend and accounted for $65.69 \%$ (CK53) of the community in the control at the end of composting. Nevertheless, their abundances showed a different pattern in the red mud added test, e.g., they increased from $31.20 \%$ on day 1 to $62.00 \%$ on day 35 and finally decreased to $28.45 \%$ on day 53 . Clostridiaceae, Ruminococcaceae, Planococcaceae, Syntrophomonadaceae and Lactobacillaceae were the main families of Firmicutes in the swine manure composting. Among them, Clostridiaceae remained relatively stable at 4.32$6.57 \%$ in the control test and $2.75-9.97 \%$ in the red mud added test throughout the composting process, and finally accounted for 5.15\% and 2.75\%, respectively, in CK53 and RM53. It seems that adding red mud might result in the abundance of these bacterial groups decreasing by half by the end of composting. Clostridium,

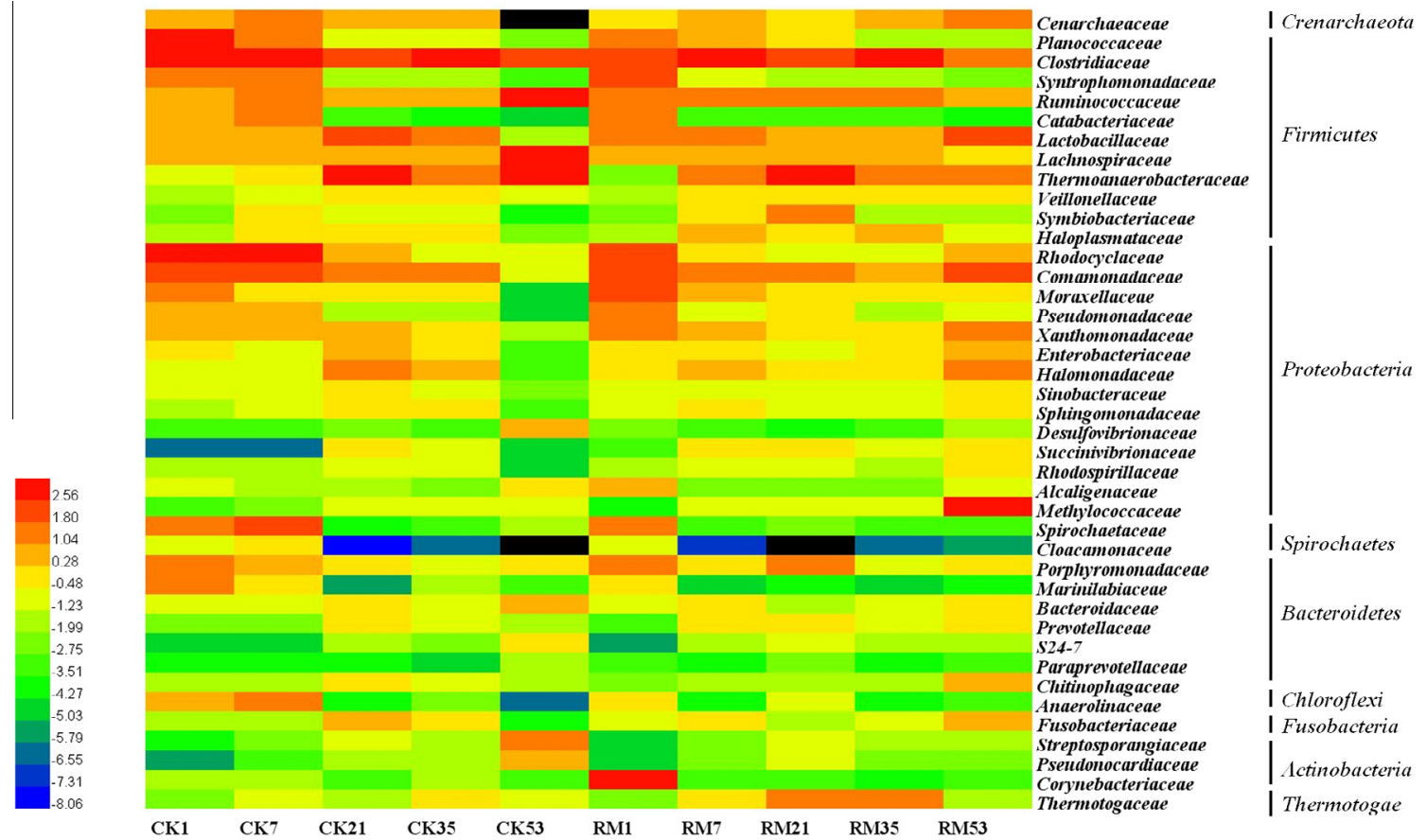

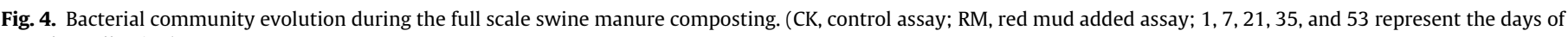
samples collection). 
the dominant genus in Clostridiaceae family, comprises mainly motile, Gram-positive, obligate anaerobic rod-shaped bacteria. These bacteria are widely distributed in soil, composts, and gastrointestinal tract of animals and humans (Rainisalo et al., 2011). During the windrow composting process, regular pile turning increases the air flow, bringing more oxygen and maintaining aerobic condition within the pile. However, there were several days in the interval between pile turnings, and during these periods, oxygen might have been consumed because of the activity of microorganisms and decomposition of organic matter. The compost piles might have been under partial anaerobic condition, evidenced by the detection of methane during composting process (FrankeWhittle et al., 2014). Therefore, partial obligate anaerobic microorganisms could survive and function under these new conditions.

Syntrophomonas (Syntrophomonadaceae), Ruminococcus (Ruminococcaceae) and Ureibacillus (Planococcaceae) abundances showed a strong positive correlation with tet and pco gene quantities (Table S4), indicating that these three genera might be the dominant hosts of tet and pco genes during the swine manure composting process. The abundances of Planococcaceae and Ruminococcaceae in the CK and RM tests were significantly different, e.g., Planococcaceae were dramatically reduced from $8.62 \%$ and $2.68 \%$ on day 1 of the CK and RM tests to $0.19 \%$ and $0.31 \%$ on day 53 of the CK and RM tests, respectively, during the swine manure composting. The abundances and variations of Syntrophomonadaceae between the CK and RM tests were similar, accounting for approximately 3\% (3.32\% in CK1 and 3.65\% in RM1) at the beginning and declining to $0.11 \%$ and $0.22 \%$ in the CK53 and RM53, respectively.

The second most abundant phylum, Proteobacteria, in the swine manure composting fluctuated smoothly and accounted for $22.22 \%$ and $24.18 \%$ of the bacterial communities, on average, in the control and red mud added tests, respectively. Pseudomonadaceae, which are strictly aerobic and never involved in fermentation, were not abundant in the fresh swine manure $(0.64 \%)$; however, they increased rapidly to $1.82 \%$ (CK1) and $3.34 \%$ (RM1) on day 1 of composting, decreased dramatically to $0.35 \%$ (CK21) and $0.77 \%$ (RM21) in the thermophilic stage, and then ultimately decreased to $0.05 \%$ (CK53) and $0.59 \%$ (RM53) at the end of the mature stage. The most abundant genus, Pseudomonas, in the family Pseudomonadaceae is ubiquitous in the environment and has been previously reported in bacterial communities of manure composts. Pseudomonas strains are capable of $\mathrm{N}_{2}$ fixation, denitrification and degradation of pollutants (Franke-Whittle et al., 2014). In addition, a previous study indicated that Pseudomonas was found to have 68 antibiotic resistance types in the Antibiotic Resistance Genes Database (Liu and Pop, 2009). Mendez et al. (1980) first examined the genetic heterogeneity of tetracycline resistance determinants from plasmids of members of the Enterobacteriaceae and Pseudomonadaceae families (Chopra and Roberts, 2001). In this study, Pseudomonas showed an obvious positive correlation with tet and pco genes (Table S4), perhaps explaining the reduction in resistance genes later in the swine manure composting process.

Actinobacteria, considered a marker for compost maturity (Xiao et al., 2011), showed an obviously increasing trend from $1.71 \%$ (CK1) to $5.46 \%$ (CK5) during the composting process. However, adding red mud might have a great influence on these bacteria. The results showed that the variation in Actinobacteria in the red mud added test was substantially difference, e.g., decreased from $11.73 \%$ (RM1) to $4.47 \%$ (RM53). This might imply that although red mud addition affected changes in bacterial abundances, it did not ultimately affect the maturity of the composting end products.

Su et al. (2015) reported completely different ARGs variations, including tet genes that significantly increased during sewage sludge composting. Their explanation was that the increasing abundance of Actinobacteria (accounting for around 50\% of the community) in the late phase of the sewage sludge composting contributed to this result. Actinobacteria are a group of antibiotic producing bacteria, often found with multi-resistance and selfresistance (Su et al., 2015). In this study, Actinobacteria were not the dominant phylum across the entire composting process, and tet and pco did not show an obvious positive correlation with Actinobacteria (Tables S3, S4).

Corynebacterium and Thermobispora were detected and identified as the main genera in the phylum Actinobacteria. Fig. 4 showed that difference in Corynebacterium (family Corynebacteriaceae) between the CK and RM tests on day 1 of composting was largely, e.g., Corynebacteriaceae were $0.31 \%$ in CK1 and $9.58 \%$ in RM1. However, these genera bacteria decreased to 0.09\% (CK21: 0.09\%; RM 21: $0.09 \%$ ) on day 21, and then Corynebacterium maintained this level in the red mud added composting (RM53: $0.09 \%$ ); and slightly increased to $0.13 \%$ at the end of the control composting. Soltan et al. reported that Corynebacterium contains potential human and animal pathogens (Soltan Mohammadi et al., 2013). The correlation analysis between the resistance genes and bacterial communities showed that Corynebacterium had an evident positive correlation with the tet and pco genes (Table S4). Therefore, it is notable that the potential pathogens and strongly correlated resistance genes both declined during swine manure composting.

Gemmatimonadetes, Spirochaetes, Acidobacteria, and Chloroflexi showed obvious changes throughout both composting tests, from $1.44 \%$ to $5.46 \%, 0.33 \%$ to $3.21 \%, 0.15 \%$ to $4.87 \%, 0.71 \%$ to $2.80 \%$ and $0.25 \%$ to $3.95 \%$, respectively. The interesting finding was that tet and pco genes showed a significantly positive correlation with Spirochaetes and Chloroflexi (Tables S3, S4), which showed evidently decreasing trends in the control test throughout the swine manure composting. In comparison, in the red mud added test, Spirochaetes presented a distinctly decreasing trend, whereas Chloroflexi showed a fluctuating but increasing trend. This might explain the less substantial reductions in tetX and tetL (Table 2) in the red mud added test at the end of composting, which showed a strong positive correlation with the abundances of these two groups (Table S4).

Planococcaceae, Rhodocyclaceae, Spirochaetaceae, Comamonadaceae and Syntrophomonadaceae were the dominant microbes in the beginning of the composting, accounting for $8.62 \%$ (CK1) and 2.68\% (RM1), 5.86\% (CK1) and 5.12\% (RM1), 3.33\% (CK1) and $3.29 \%$ (RM1), $4.30 \%$ (CK1) and $4.56 \%$ (RM1), 3.32\% (CK1) and $3.65 \%$ (RM1), respectively, and all of these decreased significantly during the thermophilic stage. Ruminococcaceae, Lachnospiraceae and Thermoanaerobacteraceae increased mainly in the mature stage and were predominant at the end of composting, accounting for $6.32 \%$ (CK53) and 1.46\% (RM53), 7.44\% (CK53) and $1.13 \%$ (RM53), 9.30\% (CK53) and 3.15\% (RM53), respectively, of the bacterial communities.

\subsection{Relationship among environmental factors, ARGs, and bacterial communities}

The relationships between environmental factors (such as temperature, $\mathrm{pH}$, and organic matter) and bacterial communities were evaluated by a redundancy analysis (RDA) (Fig. 5). Organic matter and $\mathrm{pH}$ were positively correlated with the first axis (explaining $52.73 \%$ of total variance) and thermophilic phase samples (CK1 and RM1); temperature was positively correlated with the second axis (explaining $14.29 \%$ of total variance). In this study, the swine manure composts experienced a very long thermophilic phase, when the pile temperatures went up to $55^{\circ} \mathrm{C}$ on day 4 and remained above this temperature for around 40 days. This might well explain why most of the samples concentrated upon the thermophilic phase (Fig. 5). Temperature played an important role in 


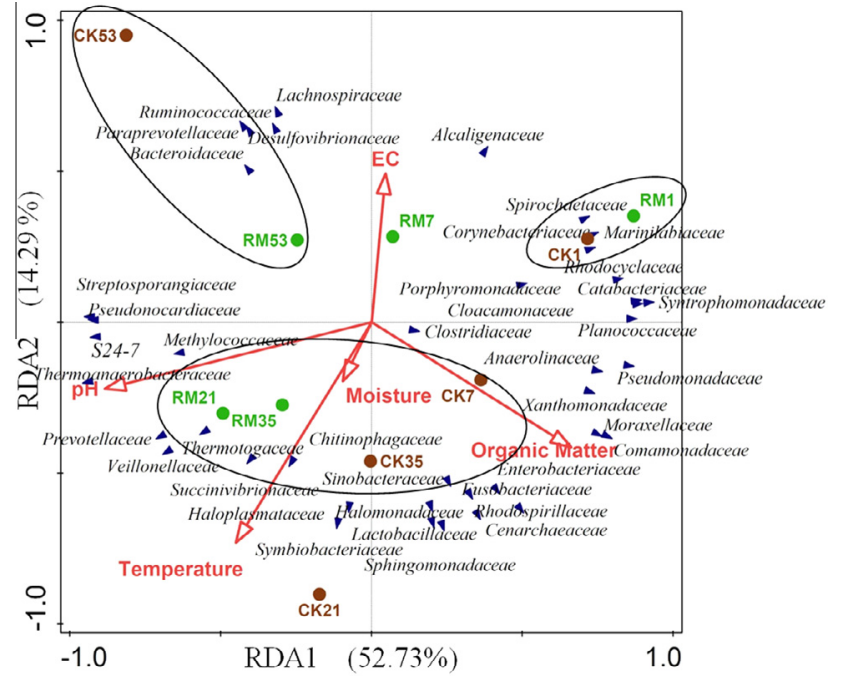

Fig. 5. Redundancy analysis assessing the relationship between environmental factors (red arrows) and microbial communities (symbols). The percentage of variation explained by each axis is showed, and the relationship was determined significant $(p<0.001$ ) based on 499 permutations. (CK, control assay; RM, red mud added assay; $1,7,21,35$, and 53 represent the days of samples collection). (For interpretation of the references to colour in this figure legend, the reader is referred to the web version of this article.)

shaping the microbial communities during the swine manure composting, which might directly or indirectly affect the variations of resistance genes. Thermophilic anaerobic digestion could significantly reduce tet genes, which might in part be due to temperature selection of distinct bacteria in sewage sludge (Diehl and Lapara, 2010). Composting could reduce various types of ARGs in livestock manure, possibly because of elevated temperatures and partial aerobic conditions in the thermophilic phase; both of these factors could destroy strict mesophilic and anaerobic bacteria found in animal guts (Su et al., 2015). These data suggested that temperature played an important role in the reduction of resistance genes and evolution of microbial communities.

Procrustes analysis was conducted by rotating the ordination of changes in the bacterial communities to match the profiles of resistance genes based on a PCA analysis, and the results indicated that most of the resistance genes and bacterial communities clustered during the composting process. The explanatory variables accounted for $66.1 \%$, and the correlation between the first two axes was significantly positive ( $R=0.91$ and 0.80 , respectively). Thus, changes in the bacterial community structure as swine manure

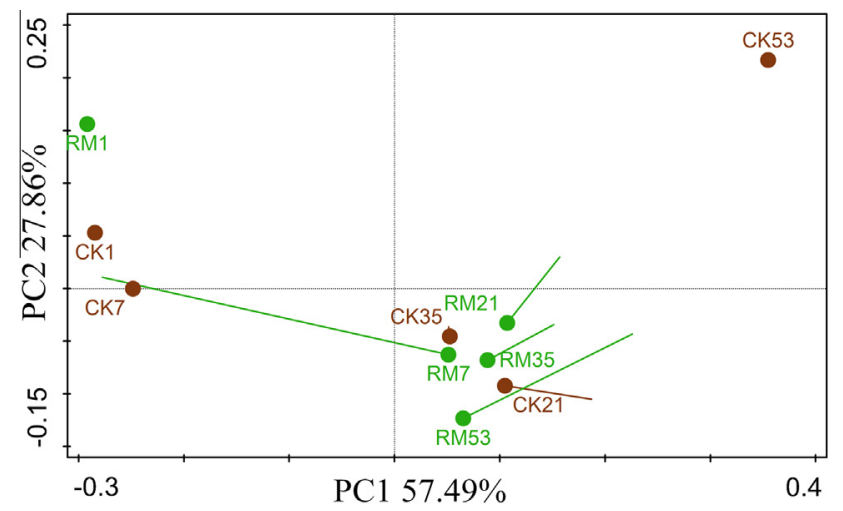

Fig. 6. Procrustes analysis of the correlation between resistance genes and microbial communities during the swine manure composting. The percentage of variation explained by each axis is showed, and the relationship was determined significant $(p<0.001)$ based on 499 permutations. (CK, control assay; RM, red mud added assay; $1,7,21,35$, and 53 represent the days of samples collection). composting proceeded contributed significantly to the resistance gene profiles (Fig. 6).

Although the red mud addition could enhance nitrogen conservation, it had an obvious influence on reduction of resistance genes and shaping of microbial communities during the full scale swine manure composting. Until now, we could not state whether these changes were beneficial or potentially harmful; however, the addition of red mud indeed hindered resistance genes removal during the swine manure composting. It is better to equilibrate both the positive and negative effects when introducing this new additive for swine manure composting.

\section{Conclusions}

ARGs in swine manure could be effectively removed through composting process ( $2.4 \log$ copies/g TS), especially during the thermophilic phase ( $1.5 \log$ copies/g TS), possibly owing to the elevated temperatures. Evolution of the bacterial communities and changes in anaerobic or aerobic conditions could also have a great influence on ARGs variation. Although addition of red mud could enhance nitrogen conservation, it obviously hindered the removal of ARGs and affected shaping of bacterial communities during composting. It is better to equilibrate both the positive and negative effects when starting to use this new additive in swine manure composting.

\section{Acknowledgements}

This work was financially supported by the Special Fund for Agro-Scientific Research in the Public Interest (No. 201303091), the National Major Science \& Technology Projects for Water Pollution Control and Management (No. 2015ZX07203-007), and the National Natural Science Foundation of China (No. 21077122).

\section{Appendix A. Supplementary data}

Supplementary data associated with this article can be found, in the online version, at http://dx.doi.org/10.1016/j.biortech.2016.06. 012 .

\section{References}

Alauzet, C., Marchandin, H., Lozniewski, A., 2010. New insights into Prevotella diversity and medical microbiology. Future Microbiol. 5 (11), 1695-1718.

Baker-Austin, C., Wright, M.S., Stepanauskas, R., McArthur, J.V., 2006. Co-selection of antibiotic and metal resistance. Trends Microbiol. 14 (4), 176-182.

Bao, S., 2000. Agricultural Chemical Analysis of Soil. China Agricultural, Beijing, pp. 56-58.

de Bertoldi, M., Vallini, G., Pera, A., 1983. The biology of composting: a review. Waste Manage. Res. 1 (2), 157-176.

Besaury, L., Bodilis, J., Delgas, F., Andrade, S., De la Iglesia, R., Ouddane, B., Quillet, L. 2013. Abundance and diversity of copper resistance genes cusA and copA in microbial communities in relation to the impact of copper on Chilean marine sediments. Mar. Pollut. Bull. 67 (1-2), 16-25.

Caporaso, J.G., Kuczynski, J., Stombaugh, J., Bittinger, K., Bushman, F.D., Costello, E.K., Fierer, N., Pena, A.G., Goodrich, J.K., Gordon, J.I., 2010. OIIME allows analysis of high-throughput community sequencing data. Nat. Methods 7 (5), 335-336.

Chan, M.T., Selvam, A., Wong, J.W.C., 2016. Reducing nitrogen loss and salinity during 'struvite' food waste composting by zeolite amendment. Bioresour. Technol. 200, 838-844.

Chopra, I., Roberts, M., 2001. Tetracycline antibiotics: mode of action, applications molecular biology, and epidemiology of bacterial resistance. Microbiol. Mol. Biol. Rev. 65 (2), 232-260.

Diehl, D.L., Lapara, T.M., 2010. Effect of temperature on the fate of genes encoding tetracycline resistance and the integrase of class 1 integrons within anaerobic and aerobic digesters treating municipal wastewater solids. Environ. Sci. Technol. 44, 9128-9133.

Edgar, R.C., Haas, B.J., Clemente, J.C., Quince, C., Knight, R., 2011. UCHIME improves sensitivity and speed of chimera detection. Bioinformatics 27 (16), 2194-2200.

Franke-Whittle, I.H., Confalonieri, A., Insam, H., Schlegelmilch, M., Körner, I., 2014 Changes in the microbial communities during co-composting of digestates. Waste Manage. 34 (3), 632-641. 
Heuer, H., Schmitt, H., Smalla, K., 2011. Antibiotic resistance gene spread due to manure application on agricultural fields. Curr. Opin. Microbiol. 14 (3), 236243.

Jiang, T., Schuchardt, F., Li, G., Guo, R., Zhao, Y., 2011. Effect of C/N ratio, aeration rate and moisture content on ammonia and greenhouse gas emission during the composting. J. Environ. Sci. 23 (10), 1754-1760.

Koike, S., Krapac, I., Oliver, H., Yannarell, A., Chee-Sanford, J., Aminov, R., Mackie, R., 2007. Monitoring and source tracking of tetracycline resistance genes in lagoons and groundwater adjacent to swine production facilities over a 3-year period. Appl. Environ. Microbiol. 73 (15), 4813.

Lee, S.M., Grass, G., Rensing, C., Barrett, S.R., Yates, C.J.D., Stoyanov, J.V., Brown, N.L., 2002. The Pco proteins are involved in periplasmic copper handling in Escherichia coli. Biochem. Biophys. Res. Commun. 295 (3), 616-620.

Li, Y., Li, W., Liu, B., Wang, K., Su, C., Wu, C., 2013. Ammonia emissions and biodegradation of organic carbon during sewage sludge composting with different extra carbon sources. Int. Biodeterior. Biodegrad. 85, 624-630.

Liu, B., Pop, M., 2009. ARDB-antibiotic resistance genes database. Nucleic Acids Res. 37 (Suppl. 1), D443-D447.

Luo, Y., Mao, D., Rysz, M., Zhou, Q., Zhang, H., Xu, L., Alvarez, J.J.P., 2010. Trends in antibiotic resistance genes occurrence in the Haihe River, China. Environ. Sci. Technol. 44 (19), 7220-7225.

Mackie, R.I., Koike, S., Krapac, I., Chee-Sanford, J., Maxwell, S., Aminov, R.I., 2006. Tetracycline residues and tetracycline resistance genes in groundwater impacted by swine production facilities. Anim. Biotechnol. 17 (2), 157-176.

Mendez, B., Tachibana, C., Levy, S.B., 1980. Heterogeneity of tetracycline resistance determinants. Plasmid 3, 99-108.

Miyatake, F., Iwabuchi, K., 2006. Effect of compost temperature on oxygen uptake rate, specific growth rate and enzymatic activity of microorganisms in dairy cattle manure. Bioresour. Technol. 97 (7), 961-965.

Nicholson, F., Chambers, B., Williams, J., Unwin, R., 1999. Heavy metal contents of livestock feeds and animal manures in England and Wales. Bioresour. Technol. 70 (1), 23-31.

Petrosino, J.F., Highlander, S., Luna, R.A., Gibbs, A.R., Versalovic, J., 2009 Metagenomic pyrosequencing and microbial identification. Clin. Chem. 55 (5), $856-866$.

Poincelot, R.P., 1975. The Biochemistry and Methodology of Composting. The Connecticut Agricultural Experiment Station.
Rainisalo, A., Romantschuk, M., Kontro, M.H., 2011. Evolution of clostridia and streptomycetes in full-scale composting facilities and pilot drums equipped with on-line temperature monitoring and aeration. Bioresour. Technol. 102 (17), 7975-7983.

Roberts, M.C., 2005. Update on acquired tetracycline resistance genes. FEMS Microbiol. Lett. 245 (2), 195-203.

Sarmah, A.K., Meyer, M.T., Boxall, A., 2006. A global perspective on the use, sales, exposure pathways, occurrence, fate and effects of veterinary antibiotics (VAs) in the environment. Chemosphere 65 (5), 725-759.

Selvam, A., Xu, D., Zhao, Z., Wong, J.W.C., 2012. Fate of tetracycline, sulfonamide and fluoroquinolone resistance genes and the changes in bacterial diversity during composting of swine manure. Bioresour. Technol. 126, 383-390.

Shen, P., Zhang, J., Zhang, J., Jiang, C., Tang, X., Li, J., Zhang, M., Wu, B., 2013. Changes in microbial community structure in two anaerobic systems to treat bagasse spraying wastewater with and without addition of molasses alcohol wastewater. Bioresour. Technol. 131, 333-340.

Soltan Mohammadi, N., Mafakheri, S., Abdali, N., Bárcena-Uribarri, I., Tauch, A., Benz, R., 2013. Identification and characterization of the channel-forming protein in the cell wall of Corynebacterium amycolatum. Biochim. Biophys. Acta (BBA) Biomembr. 1828 (11), 2574-2582.

Su, J.Q., Wei, B., Ou-Yang, W.Y., Huang, F.Y., Zhao, Y., Xu, H.J., Zhu, Y.G., 2015. Antibiotic resistome and its association with bacterial communities during sewage sludge composting. Environ. Sci. Technol. 49 (12), 7356-7363.

Wu, N., Qiao, M., Zhang, B., Cheng, W.-D., Zhu, Y.-G., 2010. Abundance and diversity of tetracycline resistance genes in soils adjacent to representative swine feedlots in China. Environ. Sci. Technol. 44 (18), 6933-6939.

Xiao, Y., Zeng, G.-M., Yang, Z.-H., Ma, Y.-H., Huang, C., Xu, Z.-Y., Huang, J., Fan, C.-Z., 2011. Changes in the actinomycetal communities during continuous thermophilic composting as revealed by denaturing gradient gel electrophoresis and quantitative PCR. Bioresour. Technol. 102 (2), 1383-1388.

Zhang, J.Y., Sui, Q.W., Li, K., Chen, M.X., Tong, J., Qi, L., Wei, Y.S., 2016. Influence of natural zeolite and nitrification inhibitor on organics degradation and nitrogen transformation during sludge composting. Environ. Sci. Pollut. Res. http://dx. doi.org/10.1007/s11356-015-5326-5.

Zhao, C., Wan, H., Wei, Y., Han, S., Ge, Z., Zheng, B., Li, H. Effects of addition of red mud on emission of greenhouse gases and ammonia from full-scale swine manure windrow composting. Environ. Eng. Manage. J., accepted. 